\title{
SOA, ERP II e Competências Organizacionais: traços de inovação na moderna gestão de TI
}

\author{
César Augusto Biancolino ${ }^{1}$ \\ Edson Luiz Riccio ${ }^{2}$ \\ Emerson Antônio Maccari ${ }^{3}$
}

\section{Resumo}

Este trabalho tem como objetivo avaliar qual é o papel das competências organizacionais que estão vinculadas ao universo de gestão da tecnologia SOA e dos sistemas ERPs no processo de sustentação do valor de uso destes aplicativos no cenário macroeconômico brasileiro, em sua perspectiva de pós-implementação. Para tal, utiliza o referencial teórico associado tanto à literatura voltada para o estudo das competências organizacionais como também à literatura voltada para o a gestão dos sistemas ERPs, com foco em sua perspectiva de principal ator da suíte de aplicativos associados à Tecnologia da Informação. A metodologia utilizada no estudo previu o desenvolvimento do método de estudo de casos múltiplos, através do qual as informações colhidas nas empresas foram analisadas em conjunto e de forma cruzada, possibilitando a identificação mais robusta das competências organizacionais e de suas respectivas aderências ao problema da pesquisa. As evidências empíricas sugerem que de fato existe um conjunto de competências organizacionais, especializada na gestão da área de TI envolvendo os aplicativos ERPs, inovação em TI e das tecnologias SOA e ERP II. Tem-se como conclusão que há três principais competências organizacionais ligadas aos sistemas ERP II que devem ser desenvolvidas pelas empresas de forma a maximizar o valor de uso desta tecnologia em função da competitividade e resultados organizacionais.

Palavras-chave: Sistemas de Informação. ERP. ERP II. SOA. Competência Organizacional.

\footnotetext{
${ }^{1}$ Doutor em Controladoria e Contabilidade pela FEA/USP. Professor do Programa de Mestrado Profissional em Gestão de Projetos da Universidade Nove de Julho - UNINOVE. End.: Av. Francisco Matarazzo, 612, Água Branca, São Paulo - SP. CEP: 05001-100 - Brasil. E-mail: biancolino@gmail.com.

${ }^{2}$ Livre Docente em Sistemas de Informação e Doutor em Administração pela FEA/USP. Professor Associado do Depto. de Contabilidade da FEA/ USP. Endereço: Av. Prof. Luciano Gualberto, 908, Cidade Universitária. CEP 05508-010 - Brasil. E-mail: elriccio@usp.br.

${ }^{3}$ Doutor em Administração pela FEA/USP. Professor do Programa de Mestrado Profissional em Gestão de Projetos e do Programa de Mestrado e Doutorado em Administração da Universidade Nove de Julho - UNINOVE. Endereço: Av. Francisco Matarazzo, 612, Água Branca, São Paulo SP. CEP: 05001-100 - Brasil.E-mail: emersonmaccari@gmail.com.

Artigo recebido em: 06/01/2011. Aceito em: 12/06/2011. Membro do Corpo Editorial Científico responsável pelo processo editorial: João Nilo Linhares. 


\section{Introdução}

Desde meados do Século XX, quando se iniciou a transformação da economia industrial para uma nova estrutura de produção e de negócios voltada à informação como um dos principais ativos de uma nova economia de âmbito global, as organizações têm investido continuamente e de forma incremental em Tecnologia da Informação (TI). Os anos da década de 1990 ficaram marcados na história como um período em que as empresas participantes deste novo cenário globalizado realizaram investimentos maciços $e$ sem precedentes no desenvolvimento, na implementação e na manutenção de sistemas de informação. Entretanto, não obstante este cenário, pesquisas desenvolvidas nos últimos anos tem apontado para conclusões divergentes sobre o valor dos investimentos em TI para as organizações. (BRYNJOLFSSON; HITT, 2000; KRAEMER; DEDRICK, 2001; JAIN, 2008).

Ainda que os investimentos em Tecnologia da Informação representem proporcionalmente valores significativos do total dos investimentos realizados pelas empresas em suas operações, os recorrentes questionamentos de natureza gerencial acerca do retorno sobre o investimento em TI são tão legítimos quanto inevitáveis. Conforme Laurindo (2006, p. 167)

Ao mesmo tempo em que surge a pressão pela justificativa dos investimentos, surge também a dificuldade de avaliálos, pois o contexto da aplicação dos recursos de TI também mudou e os aplicativos estão sendo utilizados para tarefas mais complexas e sofisticadas.

Segundo Majed (2000), cerca de 70\% das implementações de sistemas ERP chegaram ao seu final oferecendo menos funcionalidades aos usuários do que as previstas originalmente como necessárias ao pleno atendimento do fluxo de informações das empresas estudadas. Em outros casos, impactos negativos gerados por falhas nos projetos de implementação de ERPs tem sido relatados na literatura (DAVENPORT, 1998; MARKUS, 2000).

Paralelamente a estes fatos, nota-se que a problemática referente às implementações de ERPs não está limitada somente aos mecanismos de mensuração do valor destes sistemas para as organizações. De acordo com Davenport (2002), essa problemática torna-se ainda mais complexa ao considerarmos a mudança da natureza do valor agregado dos ERPs às organiza- 
ções no decorrer do tempo. De acordo com essa abordagem, os benefícios operacionais gerados pelos ERPs tornam-se presentes no quotidiano das empresas com maior antecedência que os benefícios gerenciais e estratégicos (SHANG; SEDDON, 2000).

Segundo essa visão, os benefícios operacionais advindos da utilização dos sistemas ERPs incluem melhorias nos processos transacionais e o aperfeiçoamento dos processos de negócio da organização, trazendo benefícios que, via de regra, passam a ser utilizados imediatamente no período de pós implementação, ao contrário dos benefícios gerenciais (como,por exemplo, o aperfeiçoamento do processo de tomada de decisão ou da formulação do orçamento empresarial de uma forma mais eficaz), que se manifestam um pouco mais adiante na linha do tempo.

Ainda no mesmo contexto, de acordo com a perspectiva temporal associada à fase de pós-implementação dos ERPs, o valor de uso destes aplicativos dependerá, dentre outros fatores, das competências organizacionais associadas à criação de valor e à apropriação do valor envolvidas nesta etapa do ciclo de vida do ERP. Para Mizik e Jacobson (2003), o processo de criação de valor em uma organização envolve a identificação de recursos e capacidades organizacionais internas que possam contribuir para este objetivo, entretanto, ainda segundo Mizik e Jacobson (2003), para que o valor criado pela conjunção de recursos e capacidades organizacionais seja preservado no decorrer do tempo, é preciso que a organização aproprie-se deste valor antes que os seus competidores o façam. De acordo com Mizik e Jacobson (2003, p. 63):

As empresas se deparam com a tarefa estratégica de equilibrar os dois processos (de criação de valor e de apropriação de valor) em suas estratégias e determinar como se dará o suporte para cada um deles. As empresas necessitam de forma simultânea desenvolver ou adquirir capacidades relacionadas à criação de valor que facilitem a apropriação de valor. Estes dois conjuntos de capacidades requerem investimentos financeiros substanciais e atenção permanente da gerência. A tarefa de distribuir os (limitados) recursos da organização entre as capacidades de criação de valor e de apropriação de valor exigem priorizações estratégicas e mudanças entre as mesmas. 
Nota-se pelas colocações de Mizik e Jacobson (2003) que os processos de construção e de apropriação (sustentação) do valor em uma organização são aderentes à visão de Davenport (2002), no sentido que a dinamicidade da utilização dos aplicativos ERPs gera valores de diferentes naturezas no decorrer do tempo, o que sugere que as competências organizacionais relacionadas à dinamicidade de uso e de gestão dos aplicativos ERPs tenham influência significativa neste processo.

Utilizando-se deste conjunto de considerações, o valor de uso dos aplicativos ERPs pode se analisado a partir de várias dimensões, sendo uma das principais a complexidade dos aplicativos ERPs face à sua constituição tecnológica e abrangência operacional, base da eficiência de sua operação. Essa eficiência operacional, cada vez mais, está embasada na adoção de tecnologias de maior envergadura, como a migração do modelo de ERP convencional para o modelo de ERP II, ao mesmo tempo em que as empresas procuram tornar a sua infraestrutura operacional mais eficiente e mais flexível, via adoção de ferramentas de Arquitetura Orientada a Serviços, o SOA.

\section{Problemática Associada e Questão de Pesquisa}

Como exposto, a atualização tecnológica dos aplicativos ERPs na perspectiva de longo prazo pode ser considerada uma atividade não trivial por envolver o complexo planejamento e aplicabilidade das tecnologias de caráter operacional naturais aos aplicativos ERPs (o que não permite avaliar de modo uniforme o valor de uso deste tipo de aplicativo devido às constantes mudanças de processo de negócio das organizações e de versionamento tecnológico destes sistemas).

Vistos de forma conjunta, os fatores acima descritos convergem de forma harmônica para a formulação de um construto unificado, o qual tem por finalidade permitir a instrumentalização de uma pesquisa que tenha como objeto alvo o estudo do inter-relacionamento dos seguintes fatores: (a) a aderência de novas tecnologias pelo atual ambiente tecnológico das empresas brasileiras usuárias de aplicativos ERPs envolvendo a temática do ERP II e (b) a gestão de pós-implementação continuada dos aplicativos ERPsem face destes mesmos assuntos.

A partir dessa contextualização, depreende-se que o desafio maior das organizações usuárias de sistemas ERPs, não é somente o de como criar va- 
lor sobre os investimentos realizados nestes aplicativos, mas também o de como preservar esse valor ao longo do tempo (considerando-se todo o ciclo de vida de um aplicativo ERP) para que se possa maximizar o respectivo retorno sobre o investimento realizado e manter as eventuais vantagens competitivas adquiridas ao longo do tempo. De igual maneira, a gestão contínua de pós-implementação dos aplicativos ERPs deve estabelecer formas de adaptar-se continuamente ao macroambiente regulatório e operacional em que estão inseridas as organizações, no caso deste estudo o macrocontexto brasileiro.

Nesse sentido, Kettinger (1994) coloca que os sistemas de informação que não são capazes de oferecer uma vantagem competitiva sustentável possuem apenas um valor transitório ou mesmo um valor decrescente caso uma empresa concorrente possua um sistema capaz de gerar benefícios mais consistentes. Para Kettinger (1994), a sustentabilidade do valor de TI pode ser medida comparando-se o desempenho financeiro da empresa ao de seus concorrentes, obtendo-se ou não uma vantagem competitiva. Isso é particularmente verdadeiro para os sistemas ERPse o surgimento do conceito e da tecnologia ERP II veio ao encontro da necessidade dos sistemas ERP continuarem a entregar valor às organizações, de forma incremental, de forma a gerar novas possibilidades de vantagem competitiva.

\subsection{Questão Principal da Pesquisa}

De forma a direcionar a realização do estudo, foi colocada a seguinte questão principal de pesquisa:

Como tem sido a abordagem do assunto ERP II pelas empresas no macrocenário brasileiro?

\subsection{Objetivo da Pesquisa}

Este trabalho de pesquisa, que pretende colaborar para o aprofundamento do conhecimento relacionado ao universo dos aplicativos ERPs, tem como objetivo principal explorar o mecanismo de adoção de tecnologias associadas ao conceito de ERP II que estejam vinculadas ao processo de sustentação do valor de uso dos sistemas ERPs no contexto empresarial brasileiro. 
O presente estudo foi conduzido através de uma abordagem clássica no formato qualitativo, a qual contempla a realização de revisão bibliográfica relacionada às vertentes teóricas do estudo e posteriormente complementada pela realização de pesquisa empírica com o objetivo de observar o fenômeno estudado de maneira abrangente, descobrir aspectos importantes relacionadas ao problema de pesquisa e gerar novas hipóteses derivadas da análise aprofundada dos temas relacionados ao estudo.

\subsection{Relevância do Tema e Justificativas}

Como é recorrente a todo processo científico no qual que se propõe a estudar um assunto delimitado com maior especificidade e profundidade, nota-se que a abordagem do assunto ERP II sob a ótica da vantagem competitiva sustentável ainda é incipiente e necessita ser explorado com maior profundidade. Nesse sentido, buscou-se desenvolver um trabalho que apresente subsídios para se desenvolver um modelo teórico de cunho qualitativo que reflita como se dá a abordagem do assunto ERP II pelas empresas. A inspiração para tal iniciativa baseou-se em três vertentes principais:

a) A enorme extensão e relevância do assunto "ERP II" em todas as suas dimensões humanas e tecnológicas.

b) A inexistência de um modelo teórico relacionado ao problema da pesquisa, desenvolvido a partir de uma abordagem qualitativa (investigação intensa e profunda).

c) A construção de um modelo teórico gerado a partir de estudos de casos efetuados diretamente no universo dos ERPs em particular nos aplicativos ERP II, utilizando-se de conceitos originários da teoria genérica do valor da TI para as organizações apenas como base de validação de uma teoria pré-existente, de caráter genérico. 


\section{Revisão Bibliográfica}

\subsection{SOA - Services Oriented Architecture}

Um dos pré-requisitos para melhor compreender os propósitos da tecnologia SOA e entender a sua aplicabilidade no conceito de ERP II é conhecer alguns dos conceitos-chave da área de negócios que servem de base para avaliar o impacto dessa tecnologia na estratégia de negócios e no desenho de TI das organizações. Murray (2007) descreve quatro conceitos chave que podem ser associados a esta temática e que devem ser analisados sob a ótica da gestão empresarial, com o objetivo de responder quais são as alternativas existentes para que a controladoria, enquanto área responsável por suprir aos requisitos legais e de competitividade empresarial, possa justificar o investimento que é realizado em TI. Segundo Murray (2007, p. 1):

1) Corporações costumeiramente internalizam suas atividades principais e externalizam suas atividades secundárias. Há duas razões para isso: Primeiro, qualidade e eficiência tendem a crescer em organizações que otimizam ao redor de si um conjunto de competências chave focadas no negócio. Segundo, estruturas de custo variável tendem a ser menos onerosas do que estruturas de custo fixo (economia de escala);

2) Operações com o mercado incorrem em custos de transações. Os custos associados com operações comuns da empresa com seus agentes externos (como fornecimento, negociações, monitoramento, pedidos a fornecedores) compensa em parte ou inteiramente os benefícios em potencial para melhorar o foco do negócio e oportunidades de implementar economias de escala;

3) Eficiência nos processos de relacionamento com o mercado reduzem os custos de transação. Estas eficiências aumentam a habilidade das corporações em externar suas atividades secundárias e em decorrência aumentam o foco no negócio e vantagens através de economia de escala $e$ 4) O mercado digital tem melhorado a eficiência do mercado de forma ampla, através da aplicação de tecnologia de informação. A "comoditização" de produtos (homogeneização de produtos e de interfaces) possibilita a melhoria da interoperabilidade e da eficiência de produtos. 
Através desses conceitos pode-se avaliar com maior propriedade a TI sob a égide de um ferramental que está associado à problemática de como as organizações podem melhorar de forma contínua o foco nas suas atividades chave e "externalizar" suas atividades secundárias. Por atividades secundárias entende-se as atividades ligadas aTIs que permitem as empresas alcançarem níveis de excelência em suas atividades chave, ou seja, o retorno que oferecem, através de serviços, às demais áreas da empresa. É necessário considerar, entretanto, que o modelo de "core competences" é apenas uma forma de estratégia corporativa que pode ou não ser adotado por uma determinada organização, contudo, não é apenas neste tipo de estratégia empresarial que o modelo de arquitetura orientada a serviços pode entregar uma vantagem competitiva real.

Nesses termos, é oportuno ressaltar que os gaps ou falta de aderência entre o que é demandado em termos de disponibilização de informaçõespelos departamentos operacionais de uma empresa e o que é entregue pela área de TI é um dos grandes obstáculos notadamente relevantes que sistematicamente são tratados das formas mais diversas possíveis, nem sempre se considerando os princípios acima destacados por Murray (2007).Tais constatações emergem em um cenário em que a arquitetura de TI orientada a serviços pode ser entendida como a tecnologia que permite que uma única infraestrutura de tecnologia seja utilizada para que todas as aplicações (softwares e gerenciadores de bancos de dados) existentes na empresa se "entendam" de forma integrada para criar serviços com flexibilidade suficiente para serem reutilizados entre os sistemas corporativos. Assim, com o SOA, é possível acessar apenas uma parte dos serviços existentes, sem a necessidade de utilizar o processo completo.

Dessa forma, o SOA reduz drasticamente o problema da TI geralmente não acompanhar o modelo de negócio da empresa por não ter capacidade de tratar um processo como um todo. Em outras palavras, com a utilização do SOA, o usuário de uma determinada funcionalidade de um determinado sistema e que necessita de um serviço específico, passa a operar em um ambiente em que a estrutura operacional fica em segundo plano, com diversos sistemas distintos cuidando de pequenos passos de um processo, formando, assim, uma base de dados única e criando uma maior inteligência ao ambiente de TI. 


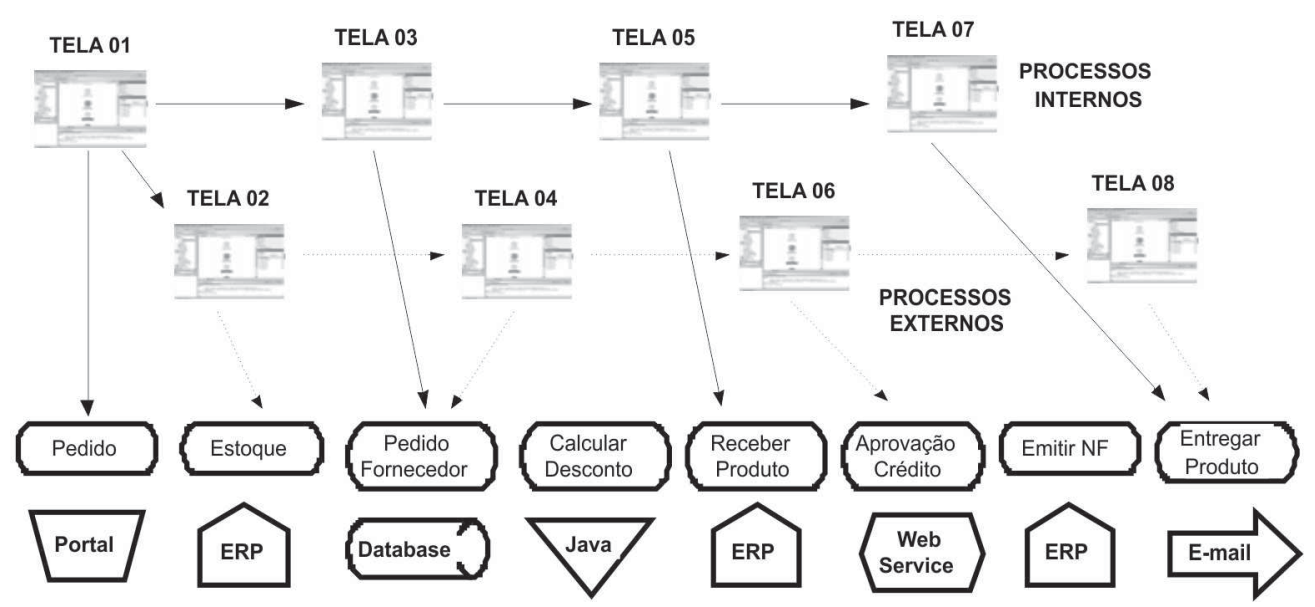

Figura 1: Processos de negócio visualizados a partir da aplicação do conceito SOA Fonte: Elaborado pelos autores

Essa tecnologia, assim definida, é capaz de propiciar a integração de funcionalidades típicas de um ERP convencional às funcionalidades típicas de outros sistemas empresariais, como por exemplo, o CRM (Customer Relationshio Management), o HCM (Human Capital Management) e SCM (Supply Chain Management), dentre outros. A potencialidade dessa sinergia de sistemas passa a ser tão intensa, que o ERP clássico torna-se potencialmente o sistema "centralizador" deste novo conjunto de funcionalidades, formando, assim, o "ERP II".

O exemplo de um determinado processo de venda no ambiente web em que vários aplicativos são necessários para executar as tarefas relacionadas a este processo, incluindo o ERP, pode ser visualizado na Figura 1. Neste exemplo, o usuário dos sistemas corporativos que opera um processo composto por várias etapas de registros e consultas informacionais utilizará oito telas para operacionalizar e visualizar as fases do processo, desde a entrada do pedido realizada via web por um cliente externo até a confirmação da entrega dos produtos realizada pela transportadora via recebimento de $e$ mail/EDI.

Nota-se, a partir da Figura 1, que cada etapa dos processos é constituída por um serviço, que pode ser reutilizado em outros processos distintos como, por exemplo, o software que calcula o desconto de uma determinada transação operacional envolvendo produtos comprados e comercializados pela empresa. Nesse âmbito, os conceitos elaborados por Murray (2007), já 
descritos, podem ser aplicados em sua integralidade, tanto sob o ponto de vista da economia de escala proporcionada por serviços únicos que atendem a várias demandas específicas como na análise da eficiência dos processos de relacionamento com o mercado, dentre outros.

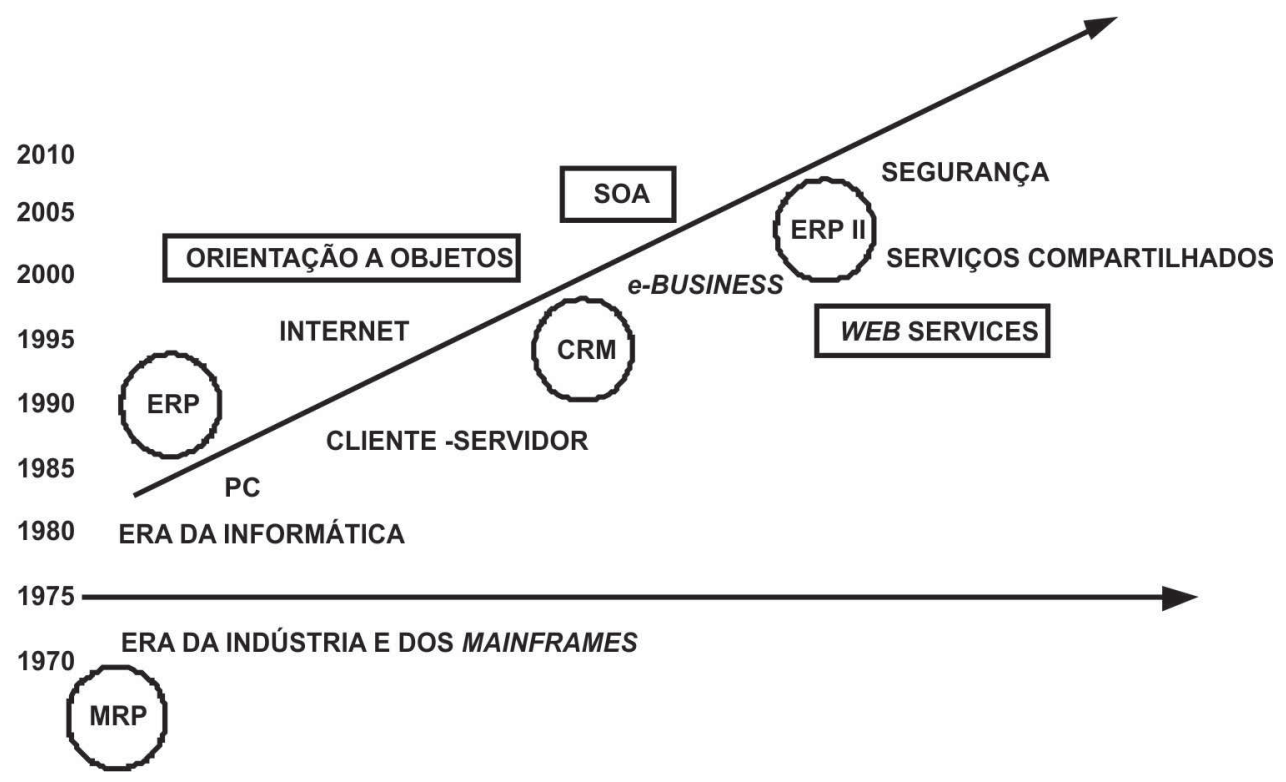

Figura 2: MRP, ERP e ERP II frente à evolução da Tecnologia da Informação Fonte: Elaborado pelos autores

Nessa mesma vertente de análise do SOA, pode-se visualizar e analisar os aspectos financeiros associados ao fato da empresa possuir uma infraestrutura de TI baseada neste tipo de arquitetura orientada a serviços. Como cada aplicativo pode gerar serviços distintos, a partir do mapeamento de processos na empresa pode-se otimizar o investimento em TI através do dimensionamento de hardware e software a partir da capacidade dos mesmos em respectivamente suportarem / oferecerem serviços.

Isso significa que se pode chegar ao melhor modelo de benefício/custo possível em termos de investimentos em TI, já que a controladoria pode dimensionar quais serviços podem ou devem ser feitos internamente à sua própria estrutura de TI e quais serviços podem ser terceirizados, ou seja, não é necessário que a empresa tenha foco em ampliar continuamente seus investimentos nesta área. Novamente os conceitos de Murray (2007) se aplicam ao fato de que as empresas podem, cada vez mais, se dedicar às suas atividades-chave (core business), através da integração possibilitada pelo SOA. 
Analisando o posicionamento do SOA por meio da linha de evolução das Tecnologias de Informação (Figura 2), percebe-se que, após terem surgido uma série de inovações tecnológicas que se sucederam desde a década de 1970, atualmente, existe uma necessidade latente no ambiente de TI de "organizar a casa", buscando segurança, integração e gerenciabilidade. Por outro lado, na era dos mainframes, a aderência entre as aplicações e a infraestrutura relacionada eram integradas e funcionalmente otimizadas. Essa característica favorecia a administração do banco de dados e o desenvolvimento de aplicativos. Todavia, os mainframes foram substituídos pelo ambiente cliente/servidor e com isso se dissolveu a dependência dentre aplicativos $e$ infraestrutura.

Nesse cenário cliente/servidor, a antiga promessa de vários fornecedores trabalharem em conjunto funcionou, mas trouxe um ônus de administração de TI muito elevado, sendo que atualmente para o futuro, os aplicativos e a infraestrutura, com a utilização do $S O A$, tendem a se acoplar novamente, todavia, regidos por padrões de comunicação universais. No ambiente $S O A$, a infraestrutura passa a se apresentar como "prestadora de serviços" para as aplicações (softwares), voltando a facilitar o desenvolvimento de soluções (sistemas) pontuais e a administração do ambiente de TI como um todo. Assim, a arquitetura de TI ou arquitetura corporativa nada mais é do que o amadurecimento de um movimento para se buscar maior gerenciabilidade, integração e segurança para o ambiente de TI. Conforme cita Cherobino (2006, p. 8):

[...] as vantagens adicionais na utilização do SOA podem ser visualizadas a partir do ponto de vista da flexibilidade envolta a esta tecnologia. Ao utilizar os serviços existentes numa estrutura corporativa, a organização ganha mais agilidade no seu dia-a-dia operacional. Qualquer mudança no ambiente de negócios, de um lançamento de produtos concorrente a uma fusão de companhias, a resposta da área de TI será mais rápida e efetiva. Com o SOA, os processos podem ser alterados rapidamente já que os serviços são disponibilizados pelos aplicativos e sistemas tanto os adquiridos no mercado quanto aqueles desenvolvidos internamente, para serem utilizados por qualquer novo sistema ou processo que os necessite, evitando a redundância. Com a consolidação da cultura de SOA, é possível otimizar o orçamento disponível para TI. A atual "Torre de 
Babel" - com inúmeros fornecedores compondo a mesma infra-estrutura e tendo de compartilhar informações em padrões distintos - é substituída por um ambiente mais transparente e interoperável, mesmo com soluções de diversos fabricantes. Isso faz cair os custos relacionados à manutenção dos sistemas e às aplicações para integração, abrindo espaço para a aquisição de novas soluções ou tecnologias. Além disso, a equipe de TI vai ter tempo disponível para se dedicar a tarefas mais estratégicas do que apenas manter a estrutura funcionando, ganhando produtividade. Outro grande dilema, o retorno sobre o investimento, fica bem mais fácil de ser medido, graças à estrutura mais transparente.

Dessa forma, evidencia-se que a tecnologia SOA não tem caráter revolucionário, mas provê uma visão de evolução na gestão de TI. Segundo Lheureux (apud CHEROBINO, 2007, p. 10) "[...] a implementação da tecnologia SOA deve seguir passos pré-determinados, sendo que a controladoria deve gerir o processo de forma precisa". Ainda de acordo com Lheureux (apud CHEROBINO, 2007, p. 10) são as seguintes as etapas de implementação do SOA que devem ser observadas:

-Introdução - É preciso definir um projeto piloto, já que a implementação segmentada reduz os investimentos $e$ permite mostrar as melhorias da iniciativa para a alta administração sem ter de enfrentar o risco de implementar o SOA em toda a empresa;

- Disseminação - Concluída a primeira fase o desafio é espalhar esse conceito para as outras áreas da empresa, aumentando o escopo de atuação $e$ as pessoas envolvidas;

-Exploração de Resultados - Qualquer projeto precisa de resultados num prazo razoável. Ao documentar os benefícios resultantes da implementação, a adoção é facilitada e a cultura é adotada pela empresa;

-Platô - Fase em que é atingido o estado da arte sobre o tema, em que o conceito pode ser conferido em sua plenitude e aproveitado na organização. Se o gestor de TI pular etapas, o fracasso está garantido.

${ }^{4}$ Benoit Lheureux, Diretor de Pesquisa do Gartner Group e especialista em SOA. 
As citações de Lheureux remetem ao fato de que a controladoria deve necessariamente procurar caminhos que melhor justifiquem os futuros investimentos em TI, de acordo com as necessidades informacionais específicas de cada organização. Essa função, específica da controladoria, deve atender aos anseios das partes relacionadas à administração da informação contábil e demais informações gerenciais / legais da empresa.

Dessa forma, nota-se que a TI deve possuir uma administração estratégica vinculada à área de tecnologia, ou seja, não é mais suportável realizar investimentos em TI sem que a máxima utilização dos atuais recursos vinculados a essas atividades estejam sendo utilizados em sua plenitude. A visão financeira relacionada à TI, cada vez mais, exigirá que a controladoria garanta o retorno dos investimentos realizados nesta área, sendo que a implementação segmentada de tecnologias integradoras, como o SOA, devem necessariamente vir a fazer parte de todos os futuros projetos de melhoria associados a estas ações. Assim, o valor competitivo do SOA pode ser expresso através das seguintes características:

a) Melhor retorno sobre o investimento sobre valores investidos em projetos de TI;

b) Redução do custo do projeto;

c) Apresentação de resultados em períodos mais curtos de tempo;

d) Capacidade de responder de forma mais ágil e flexível às exigências do negócio;

e) Maior foco na descrição dos problemas do negócio;e

f) Execuções aplicadas e alinhadas a todo o ambiente de TI.

\subsection{Arquitetura do ERP II}

Uma vez destacada a importância da tecnologia SOA frente à integração de serviços advindos de múltiplos sistemas, pode-se (ou não) considerá-la para efeito da construção dos aplicativos ERP II. A diferença básica entre a utilização ou a não utilização da tecnologia SOA na arquitetura de um aplicativo ERP II reside na forma de integração de dados e na presença ou não de interfaceamento entre aplicativos. Enquanto um ERP II convencional traz funcionalidades nativas originalmente pertencentes a outros aplicativos 
(CRM, SCM, BI e outros), o ERP II construído a partir da adoção da tecnologia $S O A$ com base na utilização de um ERP convencional não precisa, necessariamente, possuir tais funcionalidades em sua estrutura.

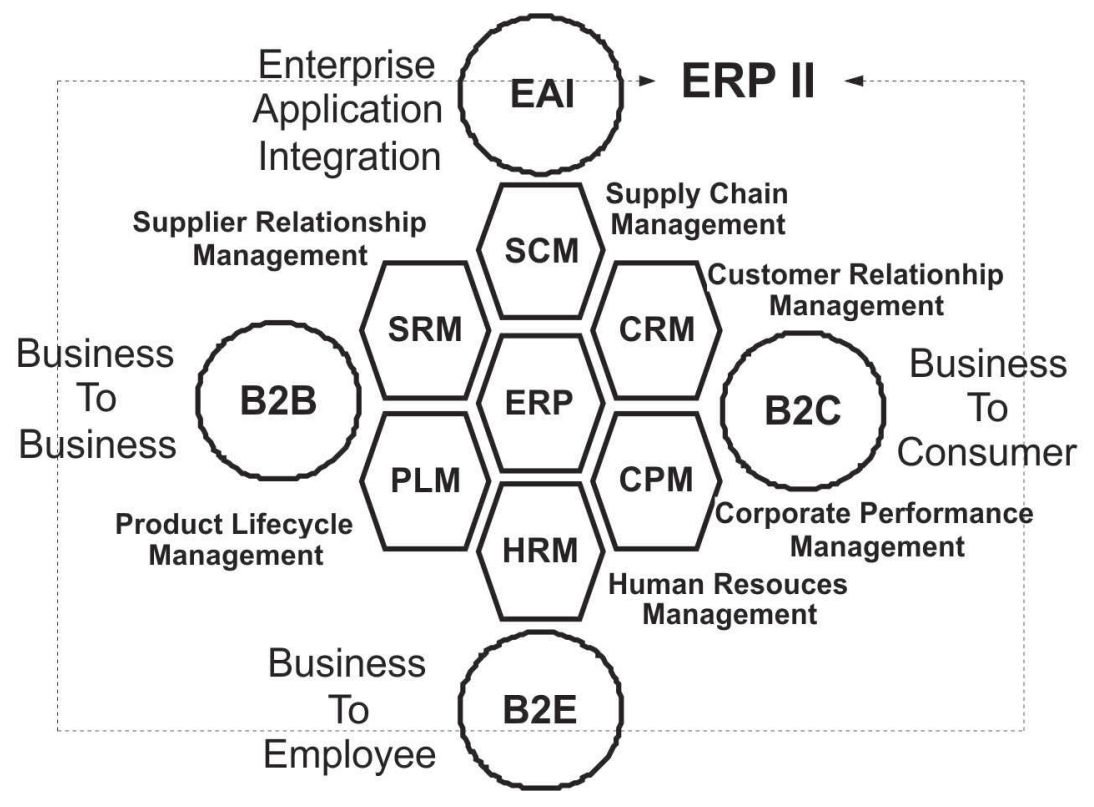

Figura 3: Estrutura conceitual do ERP II Fonte: Adaptada de Moller(2005, p. 490)

Analisada sob outro prisma, as primeiras versões dos aplicativos ERP II passaram a incorporar funcionalidades nativas de outros aplicativos, enquanto que os ERP II mais recentes tem sido desenvolvidos tanto se utilizando de novas funcionalidades nativas, também originárias primariamente de outros aplicativos, como também se utilizando dos serviços orientados a objeto, o que potencializa o conceito do ERP II como um sistema multifuncional, voltado para o front office (ou comunicação com governo, clientes e fornecedores), resguardando no entanto toda a capacidade de registrar e consolidar as informações de back office, ou internas à organização.

De acordo com Moller (2005), o ERP II inclui seis elementos que permeiam o negócio, os aplicativos e a estratégia de TI da organização. Para Moller (2005, p. 483), as seis características básicas dos aplicativos ERP II são:

(1) as funções do ERP II; (2) o domínio do negócio; (3) as funcionalidades referenciadas a este domínio; (4) os tipos 
de processos requeridos por essas funcionalidades; (5) a arquitetura de sistema que possa suportar estes processos e (6) a forma pela qual os dados são tratados por essa arquitetura.

Segundo essa definição, ainda segundo Moller (2005), com exceção da arquitetura, essas características reunidas caracterizam o ERP II como a expansão do ERP tradicional e, como conclusão, pode-se definir o ERP II como uma solução composta pela conjunção de funcionalidades do ERP tradicional e do comércio eletrônico colaborativo na cadeia de fornecedores, que está se consolidando no mercadona medida em que os aplicativos ERP clássicos estão sendo (ou serão) substituídos pelos aplicativos ERP II, de forma gradual. Essa definição pode ser representada graficamente pela Figura 3.

Segundo essa abordagem, a estrutura de um aplicativo ERP II pode ser visualizada como um sistema composto por três camadas, suportadas (ou não) pela arquitetura SOA, que pode ser expressa graficamente pela Figura 4, a qual expressa que o ERP tradicional e os aplicativos que realizam a gestão dos processos da organização (BPM - Business Process Management) que podem ou não estarem inclusos ao ERP tradicional - formam o núcleo da estrutura do aplicativo ERP II. Esse fato, como dito anteriormente, justifica-se pelo fato do ERP clássico possuir a característica de sistema integrador e centralizador dos dados provenientes das transações da organização. De outra forma, pode-se afirmar que sem a presença das funcionalidades básicas de um ERP convencional, não se pode construir o conceito de um ERP mais amplo, ou ERP II, direcionado ao ambiente externo.

Como é nítido a partir da descrição das características desses aplicativos ditos corporativos, nota-se que os mesmos possuem canais naturais de integração de dados com os ERPs. De certa forma, após a maturação do modelo ERP trabalhando com os demais sistemas corporativos, formando assim um leque de aplicativos integrados, o ERP II, já em uma fase posterior a esse modelo inicial, procura eliminar as interfaces entre taissistemas, criando uma maior integridade da base de dados. 


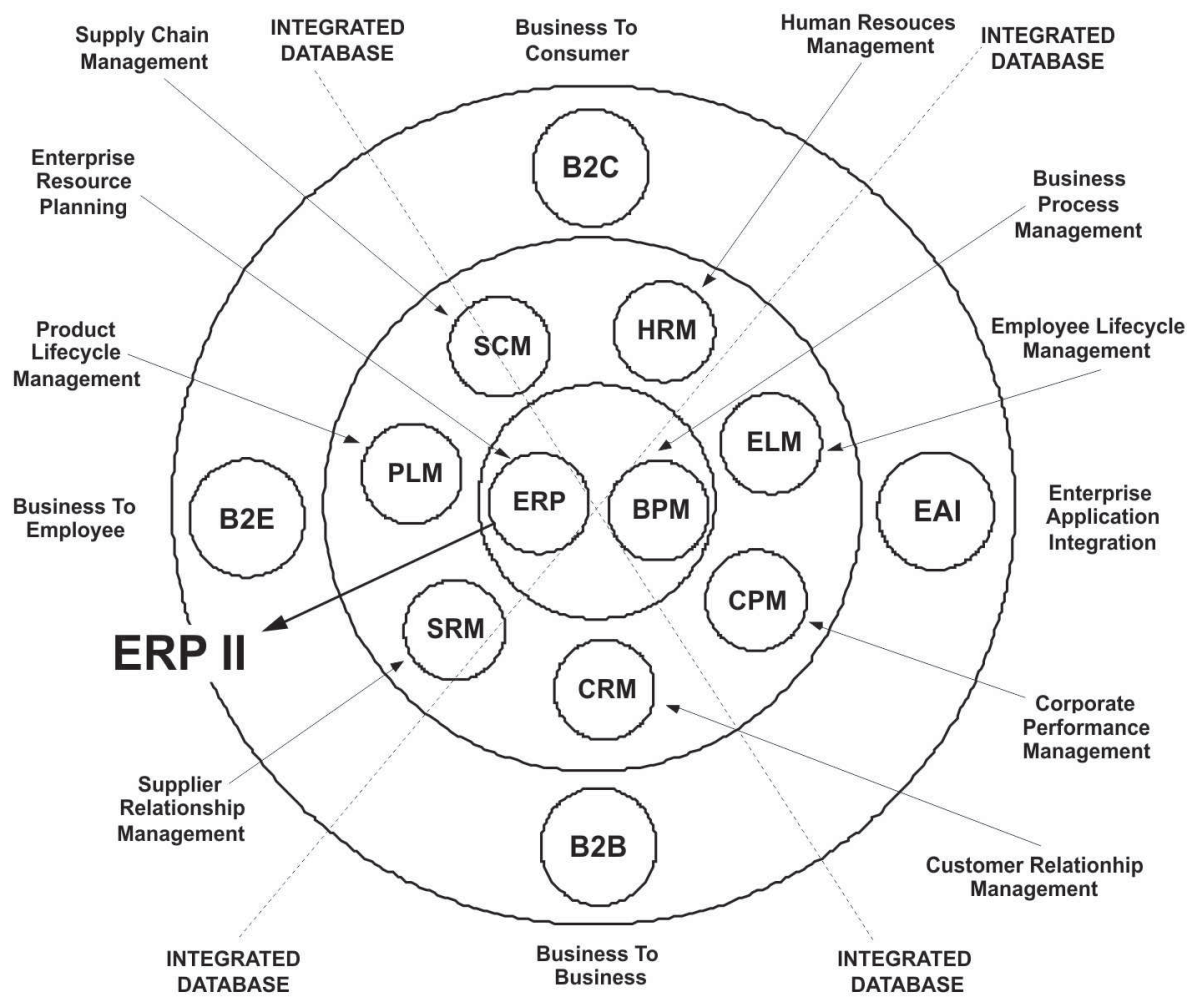

Figura 4: As camadas estruturais do aplicativo ERP II

Fonte: Elaborada pelos autores

De fato, ao constatar-se que o ERP II abarca funcionalidades que originariamente pertenciam a outras categorias de aplicativos organizacionais, o principal ganho relacionado ao desenvolvimento de tais aplicativos (ERP II) reside na constatação que um maior número de funcionalidades passaram a estar integradas de forma nativa, eliminado problemas diversos relacionados à existência de interfaces e incrementando o desempenho global destes aplicativos. Dessa forma, tanto a manutenção como a utilização da totalidade de funcionalidades do ERP II passam a ser mais simples, gerando uma melhor relação beneficio versus custo de aquisição e de manutenção.

Diante das definições que procuram definir o ERP II como um aplicativo ou um somatório de aplicativos de várias naturezas e com diversas funcionalidades diferentes, ainda que complementares, nota-se que quanto mais externa for a camada em que se encontram esses aplicativos (referenciando-se à Figura 4), mais complexa torna-se a absorção dessas funcionalidades por um único aplicativo. 
Essa visão, com relação à aplicação dos sistemas ERP como instrumento consolidador, permitem visualizar as estruturas dos ERPs como a grande base de dados corporativa dos sistemas de informação das empresas. Tal tendência significa, de acordo com Caruso; Johnson (1999), que os sistemas ERP constituem a "espinha dorsal" dos sistemas de informação das empresas. Consequentemente, como visto na definição do ERP II, esses sistemas estão estabelecendo uma plataforma comum para as várias tecnologias atualmente empregadas pelas organizações (VENKATRAMAN; HENDERSON, 1993).

\section{Metodologiada Pesquisa}

Segundo Martins e Theóphilo (2007, p. 37),

[...] o objetivo da metodologia é o aperfeiçoamento dos proce-dimentos e critérios utilizados na pesquisa. Por sua vez, métodoé o caminho para se chegar a determinado fim ou objetivo.

Segundo Martins e Theóphilo (2007, p. 37),

[...] o objetivo da metodologia é o aperfeiçoamento dos proce-dimentos e critérios utilizados na pesquisa. Por sua vez, método é o caminho para se chegar a determinado fim ou objetivo.

Dessa forma, de acordo com Demo (1995, p. 24)

[...] infere-se que a metodologia da pesquisa é equiparada a uma preocupação instrumental onde a ciência busca captar a realidade, sendo que a metodologia trata de como isso pode ser alcançado.

Nesses termos, a pesquisa empírica realizada neste trabalho pode ser classificada como exploratória, qualitativa, indutiva e foi abordada através do método de estudos de casos. Os estudos de caso são generalizáveis a proposições teóricas e não a populações ou universos. Nesse sentido, o estu- 
do de caso, como experimento, não representa uma amostragem e, ao fazer isso, seu objetivo é expandir e generalizar teorias e não enumerar frequências, realizando uma análise "generalizante" e não particularizante (YIN, 2005, p. 30).

Inserido neste contexto, o estudo de casos múltiplos adotado nesta pesquisa teve como objetivo principal, através da proposição e questões de pesquisas desenvolvidas, buscar respostas à questão principal de pesquisa, motivação deste estudo. Com base em evidências colhidas tanto através da revisão bibliográfica previamente desenvolvida, buscou-se descobrir através de observações empíricas qual é a abordagem das empresas relacionadas ao tema do ERP II no macrocenário brasileiro. O estudo de casos múltiplos foi realizado no mês de janeiro de 2011 .

\subsection{Contatos com as Empresas e Datas de Coleta de Dados}

Os contatos iniciais com as empresas / profissionais participantes do estudo de casos múltiplos foram conduzidos de acordo com as informações contidas no Quadro 1.

\begin{tabular}{|c|c|l|}
\hline Caso & Data de Contato & \multicolumn{1}{|c|}{ Observações } \\
\hline A & $10 / 01 / 2011$ & $\begin{array}{l}\text { Apresentação do Pesquisador, pedido para agendamento de } \\
\text { entrevista para o dia 24 de Janeiro de 2011; }\end{array}$ \\
\hline B & $10 / 01 / 2011$ & $\begin{array}{l}\text { Apresentação do Pesquisador, pedido para agendamento de } \\
\text { entrevista para o dia 25 de Janeiro de 2011; }\end{array}$ \\
\hline C & $10 / 01 / 2010$ & $\begin{array}{l}\text { Apresentação do Pesquisador, pedido para agendamento de } \\
\text { entrevista para o dia 26 de Janeiro de 2011; }\end{array}$ \\
\hline D & $11 / 01 / 2010$ & $\begin{array}{l}\text { Apresentação do Pesquisador, pedido para agendamento de } \\
\text { entrevista para o dia 28 de Janeiro de 2011; }\end{array}$ \\
\hline E & $12 / 01 / 2010$ & $\begin{array}{l}\text { Apresentação do Pesquisador, pedido para agendamento de } \\
\text { entrevista para o dia 31 de Janeiro de 2011; }\end{array}$ \\
\hline
\end{tabular}

Quadro 1: Agendamento das entrevistas presenciais para condução do estudo de casos múltiplos Fonte: Dados da Pesquisa

\subsection{Sítios Eletrônicos das Empresas}

Todas as empresas participantes do estudo de casos múltiplos possuem o seu sítio na internet. As páginas de todas as empresas foram acessadas an- 
tes e após as entrevistas. Os dados históricos das empresas foram coletados em suas páginas e armazenados no banco de dados de cada estudo de caso.

\subsection{Perfis Profissionais dos Entrevistados}

As informações relacionadas aos perfis profissionais dos entrevistados, bem como as áreas de atuação, sua disposição no organograma funcional da empresa estão contidas no Quadro 2.

\begin{tabular}{|l|c|c|}
\hline Caso / Entrevistado & Cargo & Área de Atuação \\
\hline Empresa A & Gerente de ERP & Tecnologia da Informação \\
\hline Empresa A & Controller Financeiro para TI & Tecnologia da Informação \\
\hline Empresa A & Gerente de Vendas & Administração De Vendas \\
\hline Empresa B & Gerente de Processos e de TI & Tecnologia da Informação \\
\hline Empresa B & Controller Financeiro & Controladoria \\
\hline Empresa B & Analista de Custos & Controladoria \\
\hline Empresa C & Gerente Regional TI & Tecnologia da Informação \\
\hline Empresa C & Collection Manager & Financeiro \\
\hline Empresa C & Supervisor Supply Chain & Chão de Fábrica \\
\hline Empresa D & CIO & Tecnologia da Informação \\
\hline Empresa D & Controller Corporativo & Controladoria \\
\hline Empresa D & Líder de Projetos & Execução de Projetos \\
\hline Empresa E & Diretor de TI & Tecnologia daInformação \\
\hline Empresa E & Gerente de Contabilidade & Contabilidade \\
\hline Empresa E & Gerente de Tesouraria & Tesouraria \\
\hline
\end{tabular}

Quadro 2: Perfis profissionais dos entrevistados

Fonte: Dados da Pesquisa

\subsection{Contextualização das Empresas}

O resumo das informações relacionadas às empresas participantes do estudo de casos múltiplos está contido no Quadro 3. 
Porte das Empresas - Através de uma escala relativa (diversas outras classificações são possíveis), apenas para referenciar o porte das empresas participantes da pesquisa, temos:

- 5 Empresas de Grande Porte (mais de 1000 funcionários)

- Faturamento bruto anual (todas as empresas): acima de 1 Bilhão de Reais

\section{Fabricantes de ERPs envolvidos:}

- Totvs (1)

- Microsoft (1)

- Oracle (1)

- SAP (2)

Quadro 3: Consolidação das informações sobre o porte das empresas e aplicativos ERP em utilização

Fonte: Dados da Pesquisa

\subsection{Construto da Pesquisa}

Para a elaboração do construto da pesquisa, foram utilizados os aspectos relevantes identificados no referencial teórico abaixo relacionado no Quadro 4:

\begin{tabular}{|l|l|}
\hline Referencial Teórico e Empírico & \multicolumn{1}{|c|}{ Aspectos Relevantes } \\
\hline $\begin{array}{l}\text { Molla eBhalla (2006) } \\
\text { Novas Funcionalidades ERP }\end{array}$ & $\begin{array}{l}\text { Gerar vantagem competitiva através da inserção } \\
\text { de funcionalidades diferenciais no ERP. }\end{array}$ \\
\hline $\begin{array}{l}\text { Molla eBhalla (2006) } \\
\text { Novos Processos ERP }\end{array}$ & $\begin{array}{l}\text { Gerar vantagem competitiva através de proces- } \\
\text { sos mais racionais e eficientes com base em } \\
\text { novas funcionalidades ERP. }\end{array}$ \\
\hline $\begin{array}{l}\text { Molla eBhalla (2006) } \\
\text { Novas Tecnologias ERP }\end{array}$ & $\begin{array}{l}\text { Gerar vantagem competitiva através da adoção de } \\
\text { novas tecnologias integradoras no âmbito do ERP. }\end{array}$ \\
\hline $\begin{array}{l}\text { Edwards (2001), Shang Seddon } \\
\text { (2000) e Rosemann e Wiese (1999) } \\
\text { Valor Orientado ao Negócio }\end{array}$ & $\begin{array}{l}\text { Participação do ERP nas ações de } \\
\text { monitoramento do desempenho da organização. }\end{array}$ \\
\hline $\begin{array}{l}\text { Edwards (2001), Shang Seddon } \\
\text { (2000), Rosemann e Wiese (1999) } \\
\text { Valor Orientado ao Cliente }\end{array}$ & $\begin{array}{l}\text { Participação do ERP nas ações de melhoria do } \\
\text { tempo de resposta a solicitações de clientes. }\end{array}$ \\
\hline
\end{tabular}

Quadro 4: Referencial Teórico: Competências organizacionais ligadas à inovação tecnológica do ERP com foco no ERP II

Fonte: Dados da Pesquisa 


\begin{tabular}{|c|c|}
\hline Referencial Teórico e Empírico & Aspectos Relevantes \\
\hline $\begin{array}{l}\text { Edwards (2001) e Shang Seddon } \\
\text { (2000) eRosemann e Wiese (1999) } \\
\text { Valor Orientado ao Cliente }\end{array}$ & $\begin{array}{l}\text { Participação do ERP nas ações de antecipação } \\
\text { das necessidades do cliente. }\end{array}$ \\
\hline $\begin{array}{l}\text { Edwards (2001) e Shang Seddon } \\
\text { (2000) eRosemann e Wiese (1999) } \\
\text { Crescimento e Aprendizado }\end{array}$ & $\begin{array}{l}\text { Participação do ERP nas ações de capacitação e } \\
\text { aprendizado acerca das atividades da empresa. }\end{array}$ \\
\hline $\begin{array}{l}\text { Edwards (2001), Shang Seddon } \\
\text { (2000) eRosemann e Wiese (1999) } \\
\text { Crescimento e Aprendizado }\end{array}$ & $\begin{array}{l}\text { Participação do ERP nas ações de suporte } \\
\text { contínuo na melhoria de processos-chave da } \\
\text { empresa. }\end{array}$ \\
\hline $\begin{array}{l}\text { Edwards (2001), Shang Seddon } \\
\text { (2000) eRosemann e Wiese (1999) } \\
\text { Valor Orientado à Finanças }\end{array}$ & $\begin{array}{l}\text { Participação do ERP como impulsionador das } \\
\text { vendas e receitas da organização. }\end{array}$ \\
\hline $\begin{array}{l}\text { Edwards (2001), Shang Seddon } \\
\text { (2000) eRosemann e Wiese (1999) } \\
\text { Valor Orientado à Estratégia }\end{array}$ & $\begin{array}{l}\text { Participação do ERP na criação de novos } \\
\text { negócios. }\end{array}$ \\
\hline $\begin{array}{l}\text { Murray (2007) } \\
\text { SOA - Service Oriented Architecture }\end{array}$ & $\begin{array}{l}\text { O mercado digital tem melhorado a eficiência do } \\
\text { mercado de forma ampla, através da aplicação } \\
\text { de tecnologia de informação. A "comoditização" } \\
\text { de produtos (homogeneização de produtos e de } \\
\text { interfaces) possibilita a melhoria da } \\
\text { interoperabilidade e da eficiência de produtos. }\end{array}$ \\
\hline $\begin{array}{l}\text { Murray (2007) } \\
\text { SOA - Service Oriented Architecture }\end{array}$ & $\begin{array}{l}\text { Eficiência nos processos de relacionamento com } \\
\text { o mercado e de produção reduzem os custos de } \\
\text { transação. Estas eficiências aumentam a habili- } \\
\text { dade das corporações em externar suas ativida- } \\
\text { des secundárias e em decorrência aumentam o } \\
\text { foco no negócio e vantagens através de econo- } \\
\text { mia de escala }\end{array}$ \\
\hline $\begin{array}{l}\text { Moller (2005) } \\
\text { ERP II }\end{array}$ & $\begin{array}{l}\text { ERP II inclui elementos que permeiam o negó- } \\
\text { cio, os aplicativos e a estratégia de TI da } \\
\text { organização. }\end{array}$ \\
\hline
\end{tabular}

Quadro 4: Referencial Teórico: Competências organizacionais ligadas à inovação tecnológica do ERP com foco no ERP II

Fonte: Dados da Pesquisa 


\subsection{Proposição Orientadora da Pesquisa (hipótese)}

a) O ERP deve possuir funcionalidades adicionais, alinhadas com o conceito de SOA e de ERP II voltadas para a gestão da produção, relacionamento com clientes, reengenharia de processos, comunicação interdepartamental e geração de novos negócios, maximizando o valor de uso do aplicativo.

Com base na questão principal de pesquisa e no referencial teórico constituinte da proposição de estudo, foram formuladas as seguintes questões auxiliares constituintesdo protocolo de pesquisa, associadas às respectivas competências organizacionais encontradas na literatura, as quais estão descritas no Quadro 5.

Q1 - A sua área de negócio tem participado das decisões relacionadas à adoção de novas funcionalidades pertencentes ao conceito do ERP II no âmbito do aplicativo ERP?

Competência Organizacional Teórica Associada 1: Capacidade da área de negócio em interagir com as demais áreas usuárias do aplicativo ERP da empresa estimulando-as a analisar os ganhos e os impactos derivados da adoção de novas tecnologias e funcionalidades do aplicativo ERP II, capitaneando propostas de inovação junto à alta administração da empresa.

Q2 - Na visão de sua área de negócio, a tecnologia associada ao conceito do ERP II pode influenciar o desenho de processos de negócios da empresa vinculados ao aplicativo ERP?

Competência Organizacional Teórica Associada 2: Capacidade da área de negócio em integrar as visões de modelagem de processos no âmbito do aplicativo ERP e da adoção de novas tecnologias no âmbito do conceito do ERP II, de forma realizar projetos de caráter holístico com potencial de geração de valor para a empresa.

Q3 - A área de negócio possui recursos técnicos e humanos para incrementar na linha do tempo a maior e melhor utilização da tecnologia ERP II?

Competência Organizacional Teórica Associada 3: Capacidade da área de negócio em viabilizar tecnicamente e funcionalmente a utilização do aplicativo ERP no âmbito de novas tecnologias e funcionalidades derivadas do conceito do ERP II, de forma a agregar valor às áreas de negócio.

Quadro 5: Protocolo de Pesquisa e Competências Organizacionais Teóricas associadas Fonte: Dados da Pesquisa 


\section{Análise dos Resultados}

\subsection{Análise Cruzada das Informações Relacionadas à Questão 1}

Após analisar as respostas associadas à primeira questão do protocolo de pesquisa é possível chegarmos a alguns resultados parciais da pesquisa. Nesses termos, a primeira observação relevante é a de que as áreas pesquisadas atribuem à área de $\mathrm{TI}$ a responsabilidade de conduzir o assunto ERP II no âmbito da empresa. Como é passível de observação, de forma unânime, as áreas de TIs das empresas possuem grande aderência ao tema, sendo as condutoras naturais deste processo de construção e disseminação da tecnologia ERP II nas empresas.

Por meiodos relatos colhidos tanto junto às áreas de TI como nas demais áreas das empresas, a opção pela adoção da tecnologia ERP II é de cunho estratégico, sendo as iniciativas nesta área fomentadas pela alta direção das empresas, e não propriamente uma opção tomada de forma isolada pelas áreas respondentes. Ainda de acordo com os relatos colhidos, este fato é motivado tanto por motivos técnicos como orçamentários, já que as áreas usuárias entrevistadas declararamnão possuir competência técnica para conduzir a aquisição deste tipo de tecnologia, além de não possuírem, de forma isolada, autonomia orçamentária para conduzirem a aquisição de pacotes tecnológicos vinculados à tecnologia ERP II.

Como se pode observar no Quadro 6, incluindo as áreas de TI das empresas, somente $53 \%$ das áreas pesquisadas confirmam ter algum tipo de influência na tomada de decisão com relação à adoção da tecnologia ERP II, o que denota que esta tecnologia, por ser de ampla difusão e utilização, não está centrada nas diversas áreas usuárias que, ocasionalmente, podem ou não opinar sobre a necessidade ou a conveniência de adotar a tecnologia ERP II.

Adicionalmente, nota-se que as áreas operacionais das empresas são as que possuem o menor poder de decisão sobre a adoção da tecnologia ERP II, principalmente em função do notório processo de "terceirização" sobre a escolha e implementação de novas tecnologias da informação que normalmente são delegadas à área de TI que, por possuir uma visão mais holística dos recursos de TI e das necessidades das áreas usuárias, acabam por capitanear o processo decisório junto à alta administração das empresas. 
Uma análise bidimensional simplificada associada ao conjunto de respostas colhidas nas empresas em suas respectivas unidades de análise (áreas das empresas) e relacionada à competência organizacional sugerida 1 pode ser analisada no Quadro 6:

\begin{tabular}{|l|c|c|c|c|}
\hline Competência 1 & $\begin{array}{c}\text { Área: } \\
\text { TI }\end{array}$ & $\begin{array}{c}\text { Área: } \\
\text { Financeira }\end{array}$ & $\begin{array}{c}\text { Área: } \\
\text { Operacional }\end{array}$ & $\begin{array}{c}\text { Convergência entre } \\
\text { áreas (1) }\end{array}$ \\
\hline Empresa A & Sim & Não & Não & Tende ao NÃO \\
\hline Empresa B & Sim & Sim & Não & Tende ao SIM \\
\hline Empresa C & Sim & Não & Não & Tende ao NÃO \\
\hline Empresa D & Sim & Não & Sim & Tende ao SIM \\
\hline Empresa E & Sim & Sim & Não & Tende ao SIM \\
\hline $\begin{array}{l}\text { Convergência } \\
\text { entre áreas das } \\
\text { empresas (2) }\end{array}$ & SIM & $\begin{array}{c}\text { Tende ao } \\
\text { NÃO }\end{array}$ & $\begin{array}{c}\text { Tende ao } \\
\text { NÃO }\end{array}$ & $\begin{array}{c}\text { Aderência Geral } \\
\text { SIM: } 53 \%\end{array}$ \\
\hline
\end{tabular}

Quadro 6: Aderência entre a competência organizacional virtual 1 e as visões das unidades de análise

Fonte: Dados da Pesquisa

\subsection{Análise Cruzada das Informações Relacionadas à Questão 2}

A análise das respostas obtidas relacionadas à segunda questão do protocolo de pesquisa permite realizar algumas inferências. A primeira observação relevante é a de que de forma praticamente unânime, as áreas das empresas pesquisadas concordaram que a adoção da Tecnologia ERP II tem alterado o desenho dos processos convencionais operacionalizados pela tecnologia ERP. Tal observação deriva do fato que as áreas entrevistadas, em maior ou menor grau, convergem para a opinião que a tecnologia ERP convencional não suporta de maneira integral as necessidades operacionais $e$ informacionais correntes.

Em adição a essa observação, nota-se através do posicionamento das áreas de TI das empresas que a temática do desenho de processos e do ganho incremental em termos de funcionalidades disponíveis aos usuários fi- 
nais é uma preocupação constante e na opinião das áreas de TI, relevante. Tal constatação remete ao fato que as áreas de TI são as mais solicitadas pelas áreas operacionais e administrativas das companhias em termos de desenho e viabilização de soluções tecnológicas que propiciem novas soluções às demandas informacionais nascentes, a maior parte delas associadas às limitações de abrangência da tecnologia ERP convencional.

De acordo com as áreas de finanças das empresas consultadas, a tecnologia ERP II flexibiliza o tratamento das conciliações contábeis e financeiras existentes entre as empresas e as partes relacionadas, de forma a incluir no mesmo processo etapas de validação concernentes às atividades transacionais que anteriormente estavam limitadas ao escopo da tecnologia ERP. Segundo as áreas financeiras, mais do que uma nova possibilidade tecnológica, as funcionalidades disponibilizadas pela tecnologia ERP II trazem ainda maior confiabilidade e agilidade no tratamento das transações que envolvem terceiros, de forma que estabeleceram novos patamares de produtividade e prazos de fechamento incrementais em relação aos mesmos prazos derivados da utilização do sistema ERP convencional.

De forma similar, as áreas operacionais das empresas entrevistadas, com exceção da empresa B, a qual não estabelece contatos frequentes com partes relacionadas à empresa, reconhecem a tecnologia ERP II como fundamental para dar vazão à constante pressão por resultados tanto de produção como de logística. Tal constatação permite inferir que a tecnologia associada ao conceito de ERP II permite que as empresas agreguem valor aos seus processos, tornando a empresa melhor preparada para alcançar os seus objetivos. Uma análise bidimensional simplificada associada ao conjunto de respostas colhidas nas empresas em suas respectivas unidades de análise (áreas das empresas) e relacionada à competência organizacional sugerida 2 pode ser analisada no Quadro 7: 


\begin{tabular}{|l|c|c|c|c|}
\hline Competência 2 & $\begin{array}{c}\text { Área: } \\
\text { TI }\end{array}$ & $\begin{array}{c}\text { Área: } \\
\text { Financeira }\end{array}$ & $\begin{array}{c}\text { Área: } \\
\text { Operacional }\end{array}$ & $\begin{array}{c}\text { Convergência entre } \\
\text { áreas (1) }\end{array}$ \\
\hline Empresa A & Sim & Sim & Sim & SIM \\
\hline Empresa B & Sim & Sim & Não & Tende ao SIM \\
\hline Empresa C & Sim & Sim & Sim & SIM \\
\hline Empresa D & Sim & Sim & Sim & SIM \\
\hline Empresa E & Sim & Sim & Sim & SIM \\
\hline $\begin{array}{l}\text { Convergência } \\
\text { entre áreas das } \\
\text { empresas (2) }\end{array}$ & SIM & SIM & $\begin{array}{c}\text { Tende ao } \\
\text { SIM }\end{array}$ & $\begin{array}{c}\text { Aderência Geral } \\
\text { SIM: } 93 \% \\
\text { NÂO: 7\% }\end{array}$ \\
\hline
\end{tabular}

Quadro 7: Aderência entre a competência organizacional virtual $2 e$ as visões das unidades de análise

Fonte: Dados da Pesquisa

\subsection{Análise Cruzada das Informações Relacionadas à Questão 3}

Após a interpretação das respostas obtidas junto aos entrevistados associadas à terceira questão do protocolo de pesquisa é possível observar alguns resultados parciais da pesquisa. A primeira observação é que o conceito de ERP II tem sido aplicado de forma significativa pelas áreas das empresas que possuem este tipo de funcionalidade em utilização. De uma forma geral, os entrevistados reconheceram que as atividades operacionais às quais estão vinculados necessitam de recursos tecnológicos e humanos(capacitados) associados ao conceito de ERP II para serem viabilizadas, ainda que o tipo de aplicação e o tipo de tecnologia utilizada sejam diferenciados entre as empresas.

Após a compilação dos resultados, como descrito no Quadro 8, observou-se que as áreas de TI das empresas possuem unanimidade em reconhecer a aplicabilidade do conceito da tecnologia ERP II em seu quotidiano técnico e humano, ao passo que esse mesmo fenômeno não se repetiu na mesma intensidade nas demais áreas das demais empresas. Nesse aspecto, a área operacional da empresa $\mathrm{E}, e$ as áreas financeiras das empresas $\mathrm{D} e \mathrm{E}$ não reconheceram a tecnologia ERP II como presente em suas atividades, o que denota um descolamento em relação às demais unidades de análise estudadas. 
De acordo com as observações realizadas nas empresas $\mathrm{D}$ e $\mathrm{E}$, no momento das entrevistas as mesmas estavam passando por um momento de transição tecnológica, a empresa $\mathrm{D}$ realizando um upgrade de versão tecnológica do sistema ERP e a empresa E a implementação de um novo sistema ERP desde a sua etapa inicial, de desenho e planejamento, em substituição a um aplicativo ERP em produção, mas tecnologicamente defasado.

Adicionalmente, foi possível observar que, a partir de diversas intensidades de aderência, todas as áreas das empresas $\mathrm{A}, \mathrm{B}$ e $\mathrm{C}$ possuem como meta agregar valor às suas atividades através da melhoria da utilização dos recursos do ERP II, ainda que as ações e providências relatadas sejam diferenciadas tanto em qualidade como em quantidade. Notou-se que quanto maior é a complexidade operacional e de logística da empresa, maior é o esforço de cada área estudada em estar em conformidade com as funcionalidades advindas da tecnologia ERP II. De forma inversa, empresas cujos processos são mais simples em comparação às demais empresas estudadas, tendem a valorizar a tecnologia ERP II com menor intensidade.Uma análise bidimensional simplificada associada ao conjunto de respostas colhidas nas empresas em suas respectivas unidades de análise (áreas das empresas) e relacionada à competência organizacional sugerida 3 pode ser analisada no Quadro 8:

\begin{tabular}{|l|c|c|c|c|}
\hline Competência 3 & $\begin{array}{c}\text { Área: } \\
\text { TI }\end{array}$ & $\begin{array}{c}\text { Área: } \\
\text { Financeira }\end{array}$ & $\begin{array}{c}\text { Área: } \\
\text { Operacional }\end{array}$ & $\begin{array}{c}\text { Convergência entre } \\
\text { áreas (1) }\end{array}$ \\
\hline Empresa A & Sim & Sim & Sim & SIM \\
\hline Empresa B & Sim & Sim & Sim & SIM \\
\hline Empresa C & Sim & Sim & Sim & SIM \\
\hline Empresa D & Sim & Não & Sim & Tende ao SIM \\
\hline Empresa E & Sim & Não & Não & Tende ao NÃO \\
\hline $\begin{array}{l}\text { Convergência } \\
\text { entre áreas das } \\
\text { empresas (2) }\end{array}$ & SIM & $\begin{array}{c}\text { Tende ao } \\
\text { SIM }\end{array}$ & $\begin{array}{c}\text { Tende ao } \\
\text { SIM }\end{array}$ & $\begin{array}{c}\text { Aderência Geral } \\
\text { SIM: } 80 \% \\
\text { NÂO: } 20 \%\end{array}$ \\
\hline
\end{tabular}

Quadro 8: Aderência entre a competência organizacional virtual 3 e as visões das unidades de análise

Fonte: Dados da Pesquisa 


\section{Conclusões}

Conclui-se que a abordagem do assunto ERP II pelas empresas brasileiras tem sido tratada de forma relevante, substancial e positiva, de forma a agregar valor ao negócio em linha com a estratégia de atuação das empresas pesquisadas. O tema ERP II não só é um item primordial na formação do planejamento estratégico de TI como sua aplicação tem sido reconhecida como relevante para os resultados das empresas que adotaram esta tecnologia. A partir dessa constatação central, em resposta à questão principal de pesquisa, derivam conclusões complementares decorrentes da análise dos resultados da pesquisa.

Nesse sentido, a proposição de estudo que fomenta a afirmação de que o ERP deve possuir funcionalidades adicionais, alinhadas com o conceito de SOA e de ERP II voltadas para a gestão da produção, relacionamento com clientes, reengenharia de processos, comunicação interdepartamental e geração de novos negócios (maximizando o valor de uso do aplicativo), pode ser analisado através de algumas vertentes, destacadas a seguir.

A primeira vertente evidencia que, em termos das avaliações efetuadas sobre as unidades de análise de uma mesma empresa, existe uma tendência à homogeneidade de percepções com relação à importância do ERP II como um fator gerador de valor no âmbito do ERP. Como observado, as empresas que possuem uma maior maturidade no uso do aplicativo ERP convencional aliado a processos de negócio mais complexos, tendem a desenvolver competências no sentido de valorizar e aplicar a tecnologia ERP II com maior ênfase, buscando o aumento da produtividade e segurança no trânsito de informações com seus parceiros de negócio.

A segunda vertente diz respeito à participação da área de TI no processo de alavancagem do ERP II no rol de soluções de TI das empresas. De acordo com o observado, as áreas de TI das empresas exercem a competência de coordenação técnica tanto no processo de aquisição e aceite das empresas em aderirem às funcionalidades do ERP II quanto na etapa de implementação das funcionalidades, quando viabilizaram a execução destes projetos como adicionais à área de TI, sem relacioná-los a nenhum processo de revolução tecnológica.

A terceira vertente diz respeito à relevância da abordagem ERP II pelas empresas. Notou-se que, apesar de terem gerado valor nas empresas, o início do processo de adoção desta tecnologia deu-se em âmbito executivo $e$ 
não nas áreas operacionais. Percebe-se através deste fato que mais do que possuir uma área de TI alinhada com as demais áreas usuárias do ERP em termos de gestão, o comando executivo da área de TI deve possuir a competência necessária para gerenciar todas as oportunidades de geração de valor que tenha origem além das fronteiras das empresas. O conceito de ERP II deixou esse fato bem evidente.

Finalmente, foi possível identificar que o ERP II é visto como um agente de integração tecnológica capaz de gerar maior volume de informações em uma mesma base de informações e de enriquecer a constituição dos processos das empresas. No domínio de pesquisa deste estudo de casos múltiplos, não ficaram evidenciados os fatores de gestão da produção e de reengenharia de processos como evidenciados na proposição da pesquisa, por outro lado,evidenciaram-se como relevantes as questões relacionadas com a tecnologia SOA como importantes artefatos de informação vinculados ao ERP II. Conclui-se, dessa forma, que o estudo aprofundado do tema ERP II é relevante, complexo e merece ser conduzido por pesquisas complementares a este estudo, de forma a formar um leque de observações independentes e complementares sobre o tema.

\section{SOA, ERP II and Organizational Competences: traces of innovation in the modern IT management}

\section{Abstract}

This research has as objective evaluates which is the role of the organizational competences that are linked to the SOA technology and ERP II systems management universe in the process of sustaining the use value of these applications in the Brazilian macro-economic scenario, in their post implementation perspective. For such, it uses the theoretical referential focused on the study of organizational competences literature as well as literature directed to the ERP's systems, focusing on the ERP II perspective of the main actor of the of applications suite related to Information Technology. The methodology used in the study predicted the development of the method of multiple case study, making possible the most robust identification of the organizational competences and of their respective adherences to the research problem. The empiric evidences suggest that in fact exists a group of organizational competences, specialized management of the IT area involving 
the ERPs applications, TI innovation and SOA and ERP II technologies. It was conclude that there are three mainly organizational competences linked to the ERP II systems that must be developed for the firms, in way to maximize the value of use of this technology in function of the competitiveness and organizational results.

Key words: Information Systems. ERP. ERP II. SOA. Organizational Competence.

\section{Referências}

BRYNJOLFSSON, E.; HITT, L. Beyond computation: Information technology, organizational transformation and business performance.Journal of Economic Perspectives. [S.1.]: 14(4), 23-48, 2000.

CARUSO, D.; JOHNSON, R.The Vision Thing.Intelligent Enterprise, p. 16 18, jan, 1999.

CHEROBINO, Vinícius. A evolução do ambiente de TI. Oracle PartnersEcosystem. Ano 1, n. 2, julho/agosto/setembro de 2006.

DAVENPORT, T. H. The return of enterprise solutions:The director's cut. Accenture. [S.1]: october 14, 2002.

DAVENPORT, T. H. Putting the enterprise into the enterprise system. Harvard Business Review. Massachusetts: 76(4), 121-133, 1998.

DEMO, P. Metodologia científica em ciências sociais. 3. ed. São Paulo: Atlas, 1995.

EDWARDS, J. B. ERP, balanced scorecard, and IT: How do they fit together?The Journal of Corporate Accounting \& Finance; [S.1]: jul./aug. 2001.

HENDERSON, J. C.; VENKATRAMAN, N. Strategic Alignment: leveraging information technology for transforming organization. IBM Systems Journal. [S.1]: V. 32, n. 1, p. 4-16, 1993.

JAIN, V. A Framework for Sustentainable ERP Value. Dissertation. The George Washington University, 2008. 
KETTINGER, W. J. Strategic information systems revisited:a study in sustainability and performance. MIS Quarterly. [S.1]: 18(1), 31-58, 1994.

KRAEMER, K.; DEDRICK, J.The Productivity Paradox: It is Resolved ? Is there a new one? What Does It All Mean for Manager's?CRITO Consortium IndustryAdvisoryBoardPanel, [S.1]: 2001.

LAURINDO, F. J. B. Gestão integrada de Processos e da tecnologia da informação. São Paulo: Atlas, 2006.

MAJED, A. Enterprise-wide information systems: The case of SAP R/3 application. In: Proceedings of the Second International Conference on Enterprise Information Systems. [S.1]: 2000, 3-8, 2000.

MARKUS, M. L. Learning from adopters' experiences with ERP:problems encountered and success achieved.Journal of Information Technology. [S.1]:15, 245-265, 2000.

MURRAY, W. SOA and the core competency model.The Prentice Hall ServiceOriented Computing Series from Thomas Erl. The SOA Magazine, april, 2007.

MARTINS, G. A.; THEÓPHILO, C. R. Metodologia da Investigação Científica para Ciências Sociais Aplicadas. São Paulo, Atlas, 2007.

MIZIK, N.; JACOBSON, R. Trading off between value creation and value appropriation: The financial implications of shifts in strategic emphasis. Journal of Marketing. [S.1]: 63-76, 2003.

MOLLA, A.; BHALLA, A. ERP and competitive advantage in developing countries: The case of an Asian company.The Electronic Journal of Information Systems in Developing Countries. [S.1]: 24(1), 1-19, 2006.

MOLLER, Charles. ERP II: a conceptual framework for next-generation enterprise systems?Journal of Enterprise Information Management, v. 18, n. 4 [ S.1]: 2005.

MURRAY, W. SOA and the core competency model.The Prentice Hall ServiceOriented Computing Series from Thomas Erl. The SOA Magazine, april, 2007. 
ROSEMANN, M.; WIESE, Jens.Measuring the performance of ERP software - A balanced scorecard approach. In: the Proceedings of 10th Australasian Conference on Information Systems (ACIS), Wellington, New Zealand, 1999.

SHANG, S.; SEDDON, P. B. A comprehensive framework for classifying benefits of ERP systems. In: The Proceedings of the Sixth Americas Conference on Information Systems. M. Chung (Ed.). Long Beach, CA, august 10-13, 2000.

YIN, R. K. Estudo de Caso: Planejamento e Métodos. 3. ed. Porto Alegre:

Bookman, 2005. 